Check for updates

Cite this: RSC Adv., 2017, 7, 45792

Received 16th August 2017

Accepted 19th September 2017

DOI: $10.1039 / \mathrm{c} 7 \mathrm{ra09075g}$

rsc.li/rsc-advances

\section{A one-pot hydrothermal synthesis of graphene/ CdS:Mn photocatalyst for photoelectrochemical sensing of glutathione $\uparrow$}

\begin{abstract}
Huili Ye, Hao Wang, Faqiong Zhao and Baizhao Zeng (DD *
A stable graphene (GR)/CdS:Mn photocatalyst was synthesized through a simple and straightforward onepot hydrothermal method, and it exhibited enhanced photoelectrochemical (PEC) response to glutathione. The catalyst was characterized by X-ray diffraction, X-ray photoelectron spectroscopy, Raman spectroscopy and UV-vis diffuse reflectance spectroscopy. It showed efficient separation of photogenerated charge carriers and low photo-corrosion. The doped $\mathrm{Mn}^{2+}$ effectively improved the band structure of CdS. Meanwhile, the introduced GR greatly enhanced and facilitated visible light absorption as well as electron transport. The GR/CdS:Mn based PEC sensor displayed more sensitive photocurrent response to glutathione than the pure CdS, CdS:Mn and GR/CdS based sensors. Furthermore, the response of the sensor was rapid and stable. The details of the additions and specific effects of each component were discussed. Under the optimized conditions, it presented wide detection range of $0.01 \mu \mathrm{M}$ to $100 \mu \mathrm{M}$, low detection limit, as well as good reproducibility. The sensor could be applied to the determination of glutathione in tomato and ketchup samples.
\end{abstract}

\section{Introduction}

Glutathione (GSH), an abundant non-protein and lowmolecular-weight mercapto compound, plays many significant roles in biological processes, including elimination of free radicals, maintenance of cellular homeostasis, radiation protection, detoxification and antioxidation. ${ }^{1}$ Its concentration level is closely associated with some diseases, such as diabetes, rheumatoid disease, HIV, Alzheimer's syndrome and cancers. ${ }^{2}$ Hence, the evaluation of GSH level is of vital significance. Hitherto, spectral, ${ }^{3}$ chromatographic, ${ }^{4}$ and electrochemical ${ }^{5,6}$ techniques have been proposed for its quantification. Nevertheless, the spectral and chromatographic methods are complicated due to pre-treatment procedures, while electrochemical detection suffers from the interference of some easily oxidative substances or a relatively high oxidation potential. ${ }^{7-9}$

Photoelectrochemical (PEC) sensing is a novel and promising analytical technique, it has attracted considerable attention. ${ }^{10}$ Owing to the complete separation of excitation source (light) and detection signal (current), PEC sensor has low background noise and high sensitivity in comparison with conventional pristine optical and electrochemical methods. ${ }^{\mathbf{1 1}}$ It

Key Laboratory of Analytical Chemistry for Biology and Medicine (Ministry of Education), College of Chemistry and Molecular Sciences, Wuhan University, Wuhan 430072, Hubei Province, P. R. China. E-mail: bzzeng@whu.edu.cn; Fax: +86-2768754067; Tel: +86-27-68752701

$\dagger$ Electronic supplementary information (ESI) available. See DOI: 10.1039/c7ra09075g can detect some hard-oxidation analytes at low applied potential, even at $0 \mathrm{~V}$. Furthermore, simple analysis device, highspeed response and relatively low-cost also make PEC sensor a competitive tool. ${ }^{12}$ The property of PEC sensor depends on the properties of photoactive materials. So far, most PEC sensors are based on nano-semiconductor materials, such as $\mathrm{TiO}_{2}{ }^{13}$ $\mathrm{ZnO},{ }^{14} \mathrm{CdS}^{15,16}$ and their derivatives. ${ }^{17}$ Among them, CdS is a popular visible-light sensitive material, it demonstrates unique photoelectrochemical properties and has good application potential. ${ }^{18,19}$

Unfortunately, CdS displays poor stability and sensitivity due to its photo-corrosion. To overcome the shortcomings, it is essential to promote the separation or inhibit the recombination of photoexcited electron-hole pairs. For CdS, two strategies have been tried. One is to introduce electron acceptor and transport matrix, such as graphene (GR), ${ }^{20}$ which could enhance light absorption and facilitate charge transport and separation. What's more, GR serves as a supporting material for CdS dispersion, simultaneously preventing its aggregation. Another is to introduce transition metal ions as they might improve the electronic and physical properties and band structure of CdS, inhibiting its light corrosion. ${ }^{17,21}$ The doped metal ions also can promote the charge separation. ${ }^{22,23}$ So far, $\mathrm{Mn}^{2+}$ is used most frequently for such purpose.

However, such modified CdS materials are mainly applied in photodegradation, ${ }^{24}$ solar cell, ${ }^{25}$ and hydrogen production, ${ }^{26}$ only a few reports concern PEC sensors. In addition, most strategies for preparing CdS semiconductors adopt a two-step chemical method, ${ }^{18}$ otherwise in need of organic solvents, 


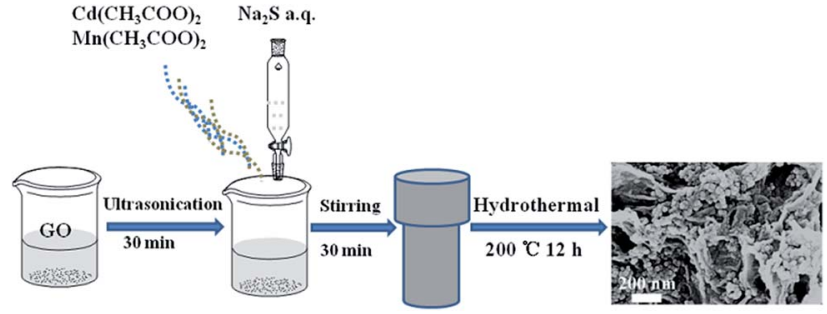

Scheme 1 Schematic diagram of the preparation of the composites.

such as ethylene glycol ${ }^{24}$ and DMSO. ${ }^{25}$ What's more, in the systems of Mn-doped CdS quantum dot sensitized solar cells reported by P. K. Santra et al. ${ }^{19}$ and a ternary complex of CdS, graphene and $\mathrm{Mn}$ fabricated by Shen's group, ${ }^{27}$ the researchers seldom explore the roles of doped $\mathrm{Mn}$ and other components. Therefore, the states of the dopants such as the valance and present form of $\mathrm{Mn}$ element and specific effects of each components need to be further discussed.

In this work, we have prepared a GR/CdS:Mn nanohybrid photocatalyst via a simple one-step hydrothermal method (Scheme 1). Water as a solvent is not only inexpensive and environmentally friendly, ${ }^{28}$ but also responsible for the hydrothermal reduction of graphitic oxide. CdS serves as the basic photoactive material, while the doped Mn element improves its band structure. Meanwhile, the GR helps to enhance the light absorption and electron transition rate. Owing to the exposed sulfhydryl group, GSH can be adsorbed on the surface of GR/ CdS:Mn composite through S-Cd bond, and it can be oxidized by photogenerated hole to glutathione disulfide (GSSG). At the same time, photogenerated electron migrates to GR through the mid-gap of $\mathrm{Mn}$, and finally transports to the ITO electrode, resulting in sustained and stable anodic photocurrent. The GR/ CdS:Mn composite shows efficient separation of photogenerated charge carriers and low photo-corrosion, the resulting PEC sensor displays much higher photocurrent response to GSH than that of pure CdS, CdS:Mn and GR/CdS based sensors.

\section{Experimental}

\subsection{Reagents and apparatus}

Graphitic oxide (GO, purity: 99\%) was purchased from Nanjing XF NANO Materials Tech Co., Ltd. (Nanjing, China). $\mathrm{Cd}\left(\mathrm{CH}_{3}{ }^{-}\right.$ $\mathrm{COO})_{2} \cdot 2 \mathrm{H}_{2} \mathrm{O}, \quad \mathrm{Na}_{2} \mathrm{~S} \cdot 9 \mathrm{H}_{2} \mathrm{O}, \quad \mathrm{Mn}\left(\mathrm{CH}_{3} \mathrm{COO}\right)_{2} \cdot 4 \mathrm{H}_{2} \mathrm{O}, \quad \mathrm{Na}_{2} \mathrm{SO}_{4}$, $\mathrm{K}_{2} \mathrm{SO}_{4}, \mathrm{CaCl}_{2}, \mathrm{Mg}\left(\mathrm{NO}_{3}\right)_{2} \cdot 6 \mathrm{H}_{2} \mathrm{O}, \mathrm{FeCl}_{3} \cdot 6 \mathrm{H}_{2} \mathrm{O}$, dopamine (DA), lactic acid (LA), uric acid (UA), ascorbic acid (AA), bovine serum albumin (BSA), glucose and glycine (Gly) were obtained from Sinopharm Chemical Regent Co., Ltd. (Shanghai, China). $\mathrm{CuSO}_{4} \cdot 5 \mathrm{H}_{2} \mathrm{O}, \mathrm{GSH}$ and GSSG were acquired from Aladdin Chemistry Co., Ltd. (Shanghai, China). All the chemicals were used without further purification. All the aqueous solutions were prepared with ultrapure water (18.25 M $)$ ). ITO substrates were from Zhuhai Kaivo Electronic Components Co., Ltd. (China).

The samples were characterized and analyzed by field emission scanning electron microscopy (FESEM, Zeiss,
Germany) with an accelerating voltage of $20 \mathrm{kV}$, X-ray diffraction data (XRD, Bruck D8 diffractometer, Germany) using $\mathrm{Cu} \mathrm{K} \alpha$ radiation $(40 \mathrm{kV}, 40 \mathrm{~mA})$ with a Ni filter, X-ray photo-electron spectroscopy (XPS, Thermal Fisher ESCALAB 250Xi, USA) with $\mathrm{Al} \mathrm{K} \alpha \mathrm{X}$-ray radiation excitation, energy-dispersive X-ray spectroscopy (EDS, Hitachi X-650 SEM, Japan), UV-vis diffuse reflectance spectra (DRS, Shimadzu UV-3600, Japan), Fourier transform infrared spectroscopy (FT-IR, Thermal Fisher, Is10, USA), and Confocal Raman Microspectroscopy (Raman, Renishaw, RM-1000, Britain) with laser of $\mathrm{Ar}^{+}$at excitation wavelength of $514.5 \mathrm{~nm}$. The photoelectrochemical experiments were performed on a CHI 830D electrochemical workstation (CH Instrument Company, Shanghai, China). The visible light source was a $500 \mathrm{~W}$ Xe lamp (SOFN instrument Co., Ltd. China). Filters of different wavelengths were from THORLABS (USA). All experiments were conducted at room temperature except mentioned otherwhere.

\subsection{Synthesis of GR/CdS:Mn nanocomposites}

The hydrothermal synthesis of GR/CdS:Mn hybrid was referred to the reported method with minor modifications. ${ }^{27}$ First of all, a certain amount of GO was dispersed in $20 \mathrm{~mL}$ ultrapure water, $0.7995 \mathrm{~g} \mathrm{Cd}\left(\mathrm{CH}_{3} \mathrm{COO}\right)_{2} \cdot 2 \mathrm{H}_{2} \mathrm{O}$ and $0.1020 \mathrm{~g} \mathrm{Mn}\left(\mathrm{CH}_{3} \mathrm{COO}\right)_{2}{ }^{-}$ $\cdot 4 \mathrm{H}_{2} \mathrm{O}$ were dissolved in $20 \mathrm{~mL}$ water. Then they were mixed under stirring. After that, $20 \mathrm{~mL} \mathrm{Na}{ }_{2} \mathrm{~S}$ solution $(3 \mathrm{mmol}$ ) was added dropwise to the mixture. The obtained mixture was transferred into a $100 \mathrm{~mL}$ Teflon-lined autoclave and heated at $200{ }^{\circ} \mathrm{C}$ for $12 \mathrm{~h}$. After cooled to room temperature, the precipitation was filtrated and washed with water for several times, and then freeze-dried to obtain GR/CdS:Mn. The mass percentage of $\mathrm{GO}$ (i.e. $0.23 \mathrm{wt} \%, 1.40 \mathrm{wt} \%, 3.50 \mathrm{wt} \%$, $7.00 \mathrm{wt} \%$, wt $\%$ meant the mass ratio of GO in the composite) and molar percentage of $\mathrm{Mn}$ (i.e. $3 \mathrm{~mol} \%, 6 \mathrm{~mol} \%, 10 \mathrm{~mol} \%$, $15 \mathrm{~mol} \%$, $20 \mathrm{~mol} \%$, mol\% was the molar ratio of $\mathrm{Mn}$ to $\mathrm{Cd}$ ) were altered to prepare different GR/CdS:Mn composites. For controlling experiments, GR, CdS, CdS:Mn and GR/CdS were synthesized. The as-prepared composites were dispersed in water to prepare $1 \mathrm{mg} \mathrm{mL}^{-1}$ suspensions for ITO modifying.

\subsection{Pretreatment of real samples}

The samples were bought from a local supermarket and the pretreatment procedure was similar to the previous reports. ${ }^{\mathbf{2 9 , 3 0}}$ The tomato and ketchup sample $(10 \mathrm{~g})$ were chopped and mashed, afterwards, they were ultrasonically extracted with $20 \mathrm{~mL} 0.10 \mathrm{M} \mathrm{Na}_{2} \mathrm{SO}_{4}$ for $2 \mathrm{~h}$ and then filtrated to get the extraction. The extraction procedure was repeated twice. The filtrate was transferred to a $50 \mathrm{~mL}$ volumetric flask and diluted to the scale with water.

\subsection{Preparation of PEC sensors}

The ITO glasses $(1 \mathrm{~cm} \times 2 \mathrm{~cm})$ were cleaned with $\mathrm{NaOH}(1 \mathrm{M})$ (in ethanol-water, v/v: $1: 1$ ) solution, washed with acetone, ultrapure water and ethanol, and dried in a oven at $60{ }^{\circ} \mathrm{C}$. The sensors were fabricated according to our previous report. ${ }^{31}$ The area of ITO glass was controlled at $0.0706 \mathrm{~cm}^{2}$ using $3 \mathrm{M}$ tape (Fig. S1a $\dagger$ ). Then $15 \mu \mathrm{L}$ of GR/CdS:Mn composite dispersion was 
coated on the ITO glass (Fig. S1b $\dagger$ ), and dried at $60^{\circ} \mathrm{C}$, followed by assembling to electrode clamp to obtain ITO/GR/CdS:Mn working electrode (Fig. S1c†).

\subsection{Measurement of PEC current}

The PEC experiments were performed on a homebuilt photoelectrochemical system. A Xe lamp equipped with a monochromator was used as the visible light irradiation source. The photocurrent was recorded by a $\mathrm{CHI} 830 \mathrm{D}$ electrochemical workstation, with a conventional three-electrode system including a modified ITO electrode as the working electrode (WE), a Pt wire as the auxiliary electrode (AE) and a saturated calomel electrode (SCE) as the reference electrode (RE). The supporting electrolyte was $0.10 \mathrm{M} \mathrm{Na}_{2} \mathrm{SO}_{4}$ aqueous solution. The distance between light source and the electrode was fixed at $10 \mathrm{~cm}$. Before PEC experiments all the solutions were adequately deaerated by purging high pure nitrogen for $15 \mathrm{~min}$.

\section{Results and discussion}

\subsection{Characterization of GR/CdS:Mn}

Fig. 1A-C shows the typical FESEM images and photos of the samples. As for yellow CdS (Fig. 1A), the particles are uniform and the sizes are about $30-40 \mathrm{~nm}$. After doping $\mathrm{Mn}^{2+}$ ions, its colour becomes a little darker and the structure becomes looser (Fig. 1B). As GR forms a 3D network structure, the loaded CdS:Mn nanoparticles are well dispersed on GR sheets with high coverage rate and show brown colour (Fig. 1C). As SEMEDS of the GR/CdS:Mn composite shown in Fig. 1D, Mn element can be detected which indicates the successful introduction. From the EDS-mapping of the composite (Fig. 1E-G), low abundance of $\mathrm{Mn}$ can be found compared with $\mathrm{Cd}$ and $\mathrm{S}$. Considering the trace amount of O from EDS, all Mn can't be $\mathrm{MnO}$, and the homogenous distribution of $\mathrm{Mn}$ in the composite opposes to discrete collections of $\mathrm{MnO}$ and proves the possible existence of MnS.

The XRD pattern of pristine GO (Fig. 2A) presents a sharp peak at $10.4^{\circ}$, corresponding to the (001) reflection of GO. ${ }^{32}$ For GR the strong diffraction peak of GO disappears and a broad weak peak at $25^{\circ}$ is observed, indicating the reduction of GO. ${ }^{18}$ There are three main peaks at $26.9^{\circ}, 44.2^{\circ}$ and $52.2^{\circ}$ for the CdS crystal, which are related to the (111), (220) and (311) cubic crystal plane (JCPDS no. 65-2887). ${ }^{33}$ After doping $\mathrm{Mn}^{2+}$, the XRD pattern of CdS:Mn displays little difference, and some peaks decline slightly, demonstrating that no extra impurity crystals form besides some lattice defects. Similar results are obtained for the GR/CdS:Mn. However, no peak of GR is observed, probably because of its relatively low diffraction and the masking effect of CdS peaks. ${ }^{34}$

XPS analysis is further used to confirm the formation of GR/ CdS:Mn composite and the reduction of GO to GR. As can be seen in Fig. $2 \mathrm{~B}$ and $\mathrm{S} 2, \uparrow$ the binding energies of $\mathrm{Cd} 3 \mathrm{~d}_{5 / 2}$ and $\mathrm{Cd}$ $3 \mathrm{~d}_{3 / 2}$ are 404.8 and $411.5 \mathrm{eV}$ respectively, while the binding energies of $\mathrm{S} 2 \mathrm{p}_{3 / 2}$ and $2 \mathrm{p}_{1 / 2}$ are 161.3 and $162.4 \mathrm{eV}$ respectively, indicating the successful generation of CdS. ${ }^{35,36}$ The binding energies of $\mathrm{Mn} 2 \mathrm{p}_{3 / 2}$ and $2 \mathrm{p}_{1 / 2}$ (insert of Fig. $2 \mathrm{~B}$ ) locate at
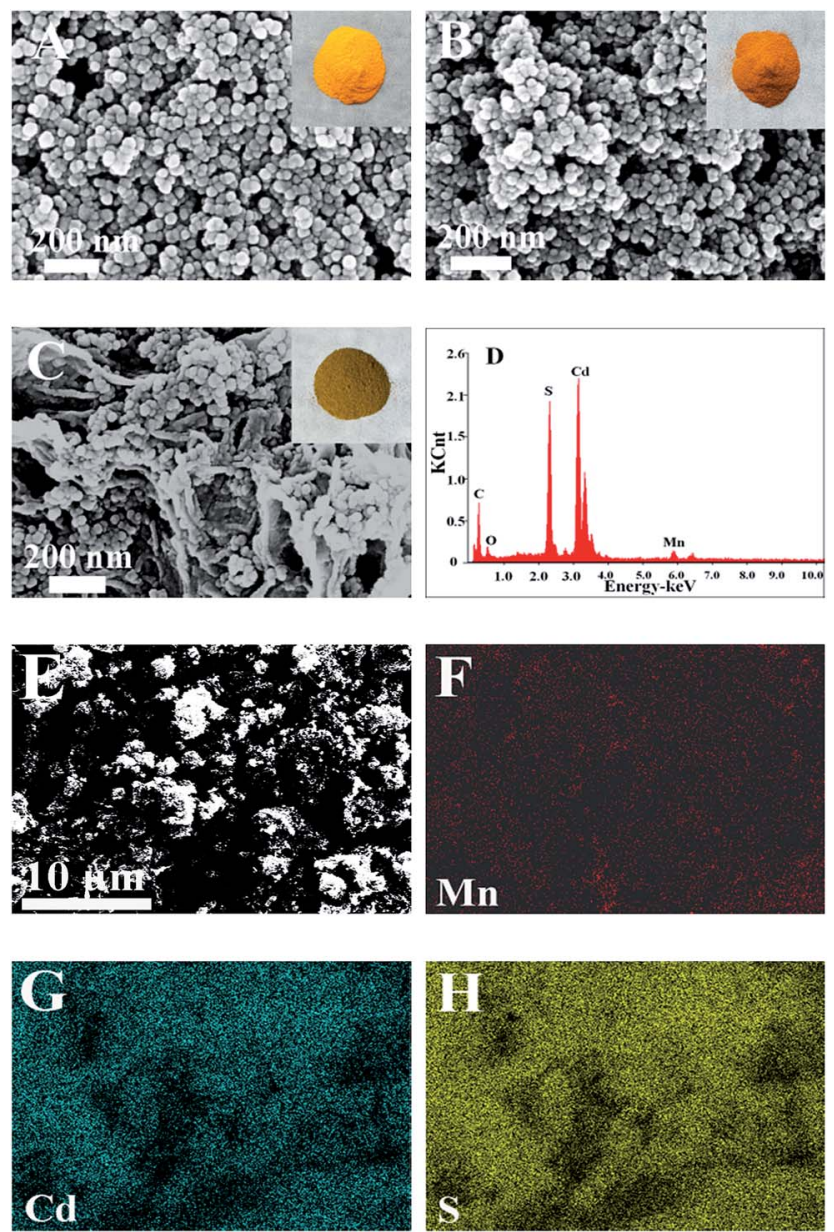

Fig. 1 The SEM images and photos (insert) of (A) CdS, (B) CdS:Mn, and (C) GR/CdS:Mn composite; (D) EDS patterns of GR/CdS:Mn composite; SEM (E) elemental mapping of the composite, Mn (F), Cd (G) and $S(H)$.

$640.8 \mathrm{eV}$ and $652.1 \mathrm{eV}$, respectively. It proves the doping of $\mathrm{Mn}^{2+} \cdot{ }^{37,38}$ In addition, the high-resolution XPS spectra of C (Fig. S2C and $\mathrm{D} \dagger$ ) shows that the $\mathrm{C}$ element presents as $\mathrm{sp}^{2}$ carbon because of the decrease of oxygen-containing groups such as $\mathrm{C}-\mathrm{O}, \mathrm{C}=\mathrm{O}$ and $\mathrm{C}-\mathrm{OH}$ in comparison with the original GO. It indicates that GO has been reduced to GR during the hydrothermal treatment.
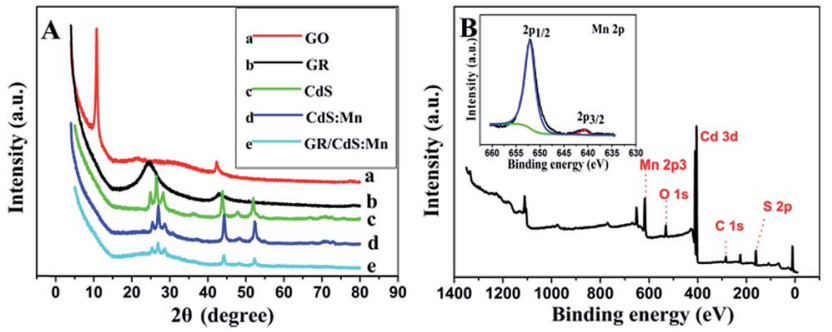

Fig. 2 (A) XRD patterns of GO (a), GR (b), CdS (c), CdS:Mn (d), GR/CdS:Mn (e); (B) XPS spectra of the GR/CdS:Mn composite and high-resolution XPS spectra of $M n 2 p$ (insert). 
The similar results can be obtained from the FTIR spectra of pristine GO, GR and GR/CdS:Mn. As can be seen in Fig. S3B, $\dagger$ for $\mathrm{GO}$, the strong band around $3420 \mathrm{~cm}^{-1}$ can be assigned to the stretching vibration of $-\mathrm{OH}$ groups. The typical characteristic peaks of other oxygen-containing groups of GO (curve a) locate at $1723 \mathrm{~cm}^{-1}, 1622 \mathrm{~cm}^{-1}, 1224 \mathrm{~cm}^{-1}, 1050 \mathrm{~cm}^{-1}$, belonging to the $\mathrm{C}=\mathrm{O}$ vibration of $-\mathrm{COOH}$ at the edge of $\mathrm{GO}$ sheets, the absorption of $-\mathrm{OH}$ bending vibration and $\mathrm{C}-\mathrm{O}-\mathrm{C}$ epoxy skeleton ring vibration, $\mathrm{C}-\mathrm{OH}$ and $\mathrm{C}-\mathrm{O}$ vibration of the alkoxy group. For GR and GR/CdS:Mn, the representative absorption bands of GO, including hydroxyl, carboxyl and epoxide groups, decrease greatly or almost completely disappear after hydrothermal treatment, indicating the successful reduction of GO. The band of $1568 \mathrm{~cm}^{-1}$ can be ascribed to the skeletal vibration of $\mathrm{C}=\mathrm{C}$ in $\mathrm{GR}$ sheets, affirming the recovery of the $\mathrm{SP}^{2}$ hybrid carbon skeleton. The band at $1209 \mathrm{~cm}^{-1}$ results from the $\mathrm{C}-\mathrm{O}$ bond of ester, which illustrates the small amount of lactone groups forming in the hydrothermal process. ${ }^{39,40}$

Fig. 3A shows the Raman spectra of CdS, CdS:Mn and GR/ CdS:Mn. The features at about 300 and $600 \mathrm{~cm}^{-1}$ correspond to the 1 longitudinal optical (1LO) and second-order LO phonon (2LO) scattering peaks of CdS, respectively. ${ }^{41}$ The intensity of the LO phonon is greatly enhanced in the CdS:Mn. In addition, the $1 \mathrm{LO}$ phonon peak of the Mn-doped CdS composite shifts slightly from $290 \mathrm{~cm}^{-1}$ to $305 \mathrm{~cm}^{-1}$. The blue shift can be attributed to the strain effect induced by the extrinsic defects in the interstitial sites (Mn dopants). ${ }^{42}$

The UV-vis diffuse reflectance spectra (DRS) of CdS, CdS:Mn and GR/CdS:Mn are shown in Fig. 3B. The band gap energy of CdS, which shows light absorption below $550 \mathrm{~nm}$, can be calculated as $2.26 \mathrm{eV}$ according to the following equation: ${ }^{43}$

$$
E_{\mathrm{g}}=1240 / \lambda
$$

where $E_{\mathrm{g}}$ is the band gap energy (eV) and $\lambda$ is the wavelength $(\mathrm{nm})$ of the absorption edge in the spectrum. After doping with Mn, the DRS spectra of CdS:Mn displays a red shift, which indicates that the band gap has been narrowed. The value can be calculated as $2.19 \mathrm{eV}$, meaning that the doped Mn makes the band gap energy of CdS decrease and improve its band structure. The GR/CdS:Mn composite demonstrates enhanced visible-light absorption due to the introduction of GR, which is beneficial to PEC sensing to some extent.
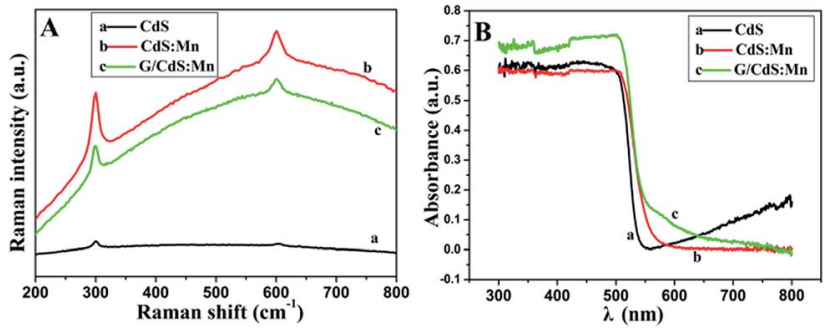

Fig. 3 (A) Raman spectra and (B) UV-vis diffuse reflectance spectra (DRS) of CdS (a), CdS:Mn (b) and GR/CdS:Mn (c).

\subsection{PEC properties of ITO/GR/CdS:Mn}

To investigate the PEC properties of GR/CdS:Mn composite, the photocurrent density of the modified ITO electrodes has been measured. Fig. 4A illustrates the photocurrent response of CdS, CdS:Mn, GR/CdS and GR/CdS:Mn modified electrodes to $1 \mu \mathrm{M}$ GSH in $0.10 \mathrm{M} \mathrm{Na}_{2} \mathrm{SO}_{4}$ aqueous solution at $0 \mathrm{~V}$ (vs. SCE). The photocurrent density of ITO/GR/CdS:Mn (d1) in the blank solution is higher than that of ITO/CdS (a1), ITO/CdS:Mn (b1) and ITO/GR/CdS (c1), due to the improved electron transport rate and reduced recombination of photogenerated charges. However, after adding GSH, its photocurrent response is also much higher than the former three electrodes. Here, the photocurrent response of ITO/GR/CdS:Mn $(\Delta I$, defined as the difference of photocurrent density with and without GSH) is $4.30 \mu \mathrm{A} \mathrm{cm}^{-2}$, while those of CdS, ITO/CdS:Mn and ITO/GR/CdS are $0.88 \mu \mathrm{A} \mathrm{cm}^{-2}, 2.42 \mu \mathrm{A} \mathrm{cm}^{-2}$ and $2.65 \mu \mathrm{Am}^{-2}$, respectively. In a word, the GR/CdS:Mn composite shows efficient separation of photogenerated charge carriers and low photo-corrosion, which displays more favourable and sensitive response to GSH. It is clear that both GR and Mn can improve the PEC activity of CdS. When they co-exist, their synergistic effect occurs and ensures a lager photocurrent enhancement.

The applied potential is of significant importance to the photocurrent response. Linear sweep voltammetry (LSV) method has been conducted to investigate its influence. As shown in Fig. 4B, without illumination (a), the photocurrent density of ITO/GR/CdS:Mn in $\mathrm{Na}_{2} \mathrm{SO}_{4}$ electrolyte is low. Under irradiation (b), it achieves a relatively high photocurrent density. The LSV corresponding to irradiation on/off presents a comparable and instantaneous photocurrent response due to PEC effect (c). It can be seen that the anodic photocurrent increases as the applied potential rises. This is because a positive potential can provide a driving force for electron transfer and facilitate the oxidization of GSH by hole. In contrast, a negative potential can inhibit the electron transfer of anode photocurrent, resulting in reduction of photocurrent. ${ }^{44,45}$ Nevertheless, when the potential is too high, the electrochemical oxidization of GSH occurs, producing an interference current. In addition, lower applied potential is beneficial to the elimination of interference from other reductive species. Thus, $0 \mathrm{~V}$ (vs. SCE) is adopted for the PEC measurement in this case.
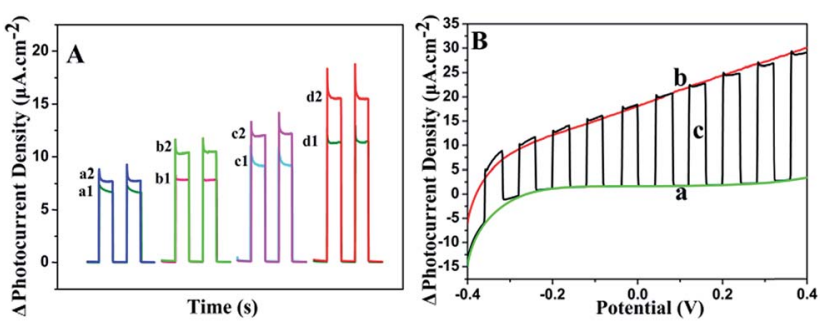

Fig. 4 (A) Photocurrent response of ITO/CdS (a), ITO/CdS:Mn (b), ITO/ GR/CdS (c) and ITO/GR/CdS:Mn (d) in the dark (1) and under illumination (2); (B) LSV of ITO/GR/CdS:Mn sensor in $1 \mu \mathrm{M}$ GSH under dark condition (a), light irradiation (b) and light "on/off" condition (c). Applied potential: 0 V (vs. SCE); irradiation wavelength: $470 \mathrm{~nm}$. 
The cyclic voltammograms (CV) of ITO/GR/CdS:Mn in the absence and presence of GSH with visible-light irradiation of $470 \mathrm{~nm}$ are recorded (Fig. S4A $\dagger$ ). GSH does not cause current peak under this conditions so that the direct detection of electrochemical oxidation signal is hard to achieve. The slow electron-transfer rate in the oxidation of GSH lead to a high overpotential. ${ }^{46}$ To further understand this point, amperometric curves are also recorded. As shown in Fig. S4B, $\dagger$ in the dark condition, no current responses for the successive addition of GSH can be observed at $0 \mathrm{~V}$. It indicates that the EC oxidation of GSH cannot occur at such low applied potential. However, in the light condition the current response signal is quite sensitive. This indicates that the current signal detected at $0 \mathrm{~V}$ results from PEC, not from the electrochemical oxidation of GSH.

\subsection{Optimization of experimental conditions}

The irradiation wavelength is one of the most important factors influencing the PEC properties. As illustrated in Fig. 5A, the photocurrent density increment $(\Delta I)$ decreases as the exciting wavelength increases from $430 \mathrm{~nm}$ to $580 \mathrm{~nm}$. At $470 \mathrm{~nm}$, the $\Delta I$ is $77.5 \%$ of that at $430 \mathrm{~nm}$. Afterward, $\Delta I$ sharply decreases with further increase of irradiation wavelength. In general, light of long wavelength is beneficial for the detection of biological samples as it has lower energy and weaker damage. ${ }^{47}$ Therefore, $470 \mathrm{~nm}$ is chosen for PEC sensing of GSH.

GR plays a significant role in the separation of photogenerated charges and in the enhancement of photocurrent density. In order to achieve an optimal photoactivity enhancement for GR-semiconductor composites, the weight addition ratio of GR in the semiconductor matrix is generally no more than $5 \mathrm{wt} \%{ }^{48}$ although the greater addition ratio of GR is able to inhibit the recombination of electron-hole pairs photogenerated from the semiconductor. As shown in Fig. 5B, the $\Delta I$ increases with the amount of introduced GO increasing from $0.23 \mathrm{wt} \%$ to $3.5 \mathrm{wt} \%$ during the synthesis of the hybrid. This is
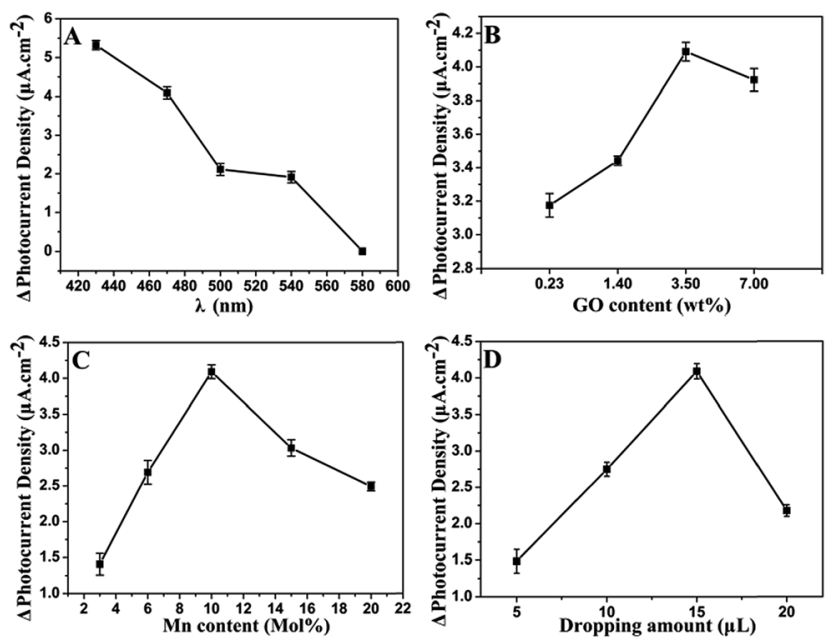

Fig. 5 Effects of (A) excitation wavelength, (B) content of GR, (C) content of doped $\mathrm{Mn}$, and (D) dropping amount of GR/CdS:Mn on the increment of photocurrent density in $0.10 \mathrm{M} \mathrm{Na}_{2} \mathrm{SO}_{4}$ containing $1 \mu \mathrm{M}$ GSH. related to the fast electron transfer of GR. However, the $\Delta I$ decreases when the amount of GO is increased further (e.g. to $7 \mathrm{wt} \%)$. It should be ascribed to the light absorption of black GR, which affects the light absorption of the photoactive material to some extent. The photos of GR/CdS:Mn composite with different GO contents can be seen in Fig. S5. $\dagger$ The color of the composite becomes darker as GO content increases. Here, the best content of GO is $3.5 \mathrm{wt} \%$ in the synthesis solution.

Fig. 5C shows the influence of $\mathrm{Mn}^{2+}$ content on photocurrent density. The doped $\mathrm{Mn}^{2+}$ in the CdS semiconductor can cause some lattice defects and further improve its band structure. Generally, lattice defects can form capture centres for the photogenerated electron-hole pairs, inhibiting the recombination of charge carriers. However, if lattice defects are too much, photocatalysis will be depressed. Herein, $10 \mathrm{~mol} \%$ (in the synthesis solution) $\mathrm{Mn}^{2+}$ is adopted in the preparation of composite.

Besides, the influence of modifying amount of GR/CdS:Mn composite has been investigated and $15 \mu \mathrm{L}$ of GR/CdS:Mn suspension $\left(1 \mathrm{mg} \mathrm{mL}^{-1}\right)$ is selected as the optimized coating amount for preparing electrode (Fig. 5D).

\subsection{PEC detection of GSH}

The developed ITO/GR/CdS:Mn photoelectrochemical sensor is applied to GSH determination. The PEC measurement is carried out in $0.10 \mathrm{M} \mathrm{Na}_{2} \mathrm{SO}_{4}$ electrolyte under the irradiation of $470 \mathrm{~nm}$ light at $0 \mathrm{~V}(v s$. SCE). Fig. 6 illustrates the photocurrent response of GSH. It can be found that the photocurrent density is proportional to the logarithm of the concentration of GSH over a wide range from $0.01 \mu \mathrm{M}$ to $100 \mu \mathrm{M}$ (Fig. 6A and B). It is wider than that of the reported electrochemical sensors based on
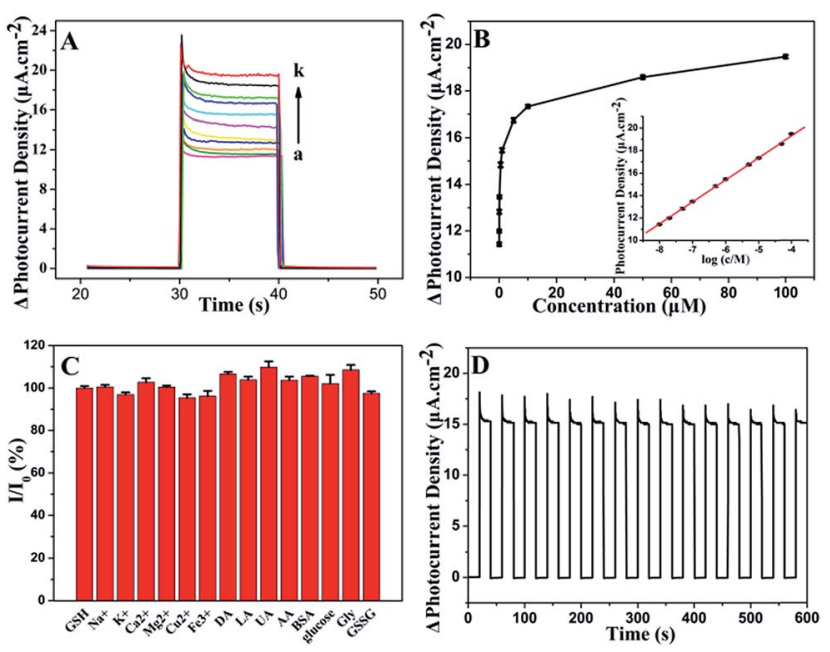

Fig. 6 (A) Photocurrent response of ITO/GR/CdS: $\mathrm{Mn}$ to GSH in $0.10 \mathrm{M}$ $\mathrm{Na}_{2} \mathrm{SO}_{4}$ solution. GSH concentration: $0,0.01,0.02,0.05,0.1,0.5,1,5$, $10,50,100 \mu \mathrm{M}$ (from a to $\mathrm{k}$ ); (B) plot of photocurrent density vs. concentration. Inset: linear calibration curve; (C) influence of $50 \mu \mathrm{M}$ $\mathrm{Na}^{+}, \mathrm{K}^{+}, \mathrm{Ca}^{2+}, \mathrm{Mg}^{2+}, \mathrm{Cu}^{2+}, \mathrm{Fe}^{3+}$, and $10 \mu \mathrm{M}$ DA, LA, AA, UA, BSA, glucose, Gly, GSSG on the response of $5 \mu \mathrm{M} \mathrm{GSH}$; (D) time-dependent photocurrent response of ITO/GR/CdS: $\mathrm{Mn}$ in $0.10 \mathrm{M} \mathrm{Na}_{2} \mathrm{SO}_{4}$ solution with light on/off. 
ordered mesoporous carbon $^{49}$ and $\mathrm{Cu}(\mathrm{OH})_{2}$-carbon ionic liquid, ${ }^{6}$ and that of PEC sensors based on flower-like $\mathrm{Cu}_{2} \mathrm{O}$ / $\mathrm{ZnO}{ }^{50} \mathrm{IrO}_{2}$-hemin- $\mathrm{TiO}_{2}$ (ref. 46) and porous $\mathrm{TiO}_{2}-\mathrm{Pt}{ }^{51}$ The linear regression equation can be expressed as $\Delta I / \mu \mathrm{A} \mathrm{cm} \mathrm{cm}^{-2}=$ $27.1+1.96 \log c / \mu \mathrm{M}\left(R^{2}=0.9995\right)$. The detection limit is 0.01 $\mu \mathrm{M}$ (based $3 \mathrm{~S} / \mathrm{N}$ ), which is lower than that of electrochemical methods concerning $\mathrm{Hg} / \mathrm{Pd}{ }^{52}$ electrochemiluminescence of CdTe QD-GO ${ }^{53}$ and PEC sensors based on Au NPs@ZnO ${ }^{14}$ and FeTPPS-TiO ${ }_{2} \cdot{ }^{47}$ The detailed comparisons are shown in Table S1. $\dagger$ As can be seen, the ITO/GR/CdS:Mn sensor presents good performance in monitoring GSH.

\subsection{Selectivity, stability and reproducibility}

The selectivity of the ITO/GR/CdS:Mn sensor is evaluated by measuring the photocurrent response of various potential interferents and other similar hole scavengers (Fig. 6C). As can be seen, the studied mental ions (i.e. $50 \mu \mathrm{M} \mathrm{Na}^{+}, \mathrm{K}^{+}, \mathrm{Ca}^{2+}, \mathrm{Mg}^{2+}$, $\mathrm{Cu}^{2+}, \mathrm{Fe}^{3+}$ ), common chemicals and biological molecules (i.e. 10 $\mu \mathrm{M}$ DA, LA, AA, UA, BSA, glucose, Gly, GSSG) shows much smaller or negligible signals, which indicates that those coexistents have little influence on the detection of GSH. A reasonable explanation for the good selectivity is the possibility of GSH adhering to the particles surface. Fig. 6D shows the time-dependent photocurrent response of the ITO/GR/CdS:Mn at repeated on/off cycles for $600 \mathrm{~s}$ under visible illumination. The stable photocurrent density indicates the inhibition of the photo-corrosion of CdS and the light stability of the hybrid. Here, the relative standard deviation (RSD) of the photocurrent density for $5 \mu \mathrm{M}$ GSH is $2.3 \%$ for five successive measurements (Fig. S6 $\dagger$ ), and the RSD for 5 different ITO/GR/CdS:Mn is $5.4 \%$, reflecting its good reproducibility. What's more, the sensor remains $91 \%$ of the initial photocurrent response after storing for 12 days at room temperature, indicating the good structural stability of the fabricated photo-anode material.

\subsection{Application}

To demonstrate the application feasibility of the as-prepared ITO/GR/CdS:Mn PEC sensor, the determination of GSH in tomato and ketchup has been conducted and the results are listed in Table 1 . Their contents are determined by this analytical method and ca. $5.93 \mathrm{mg} \mathrm{kg}^{-1}$ and $0.97 \mathrm{mg} \mathrm{kg}^{-1}$ for tomato and ketchup, respectively. The detected content of tomato is close to the report ${ }^{30}$ and the result of ketchup agrees

Table 1 Determination results of GSH in samples

\begin{tabular}{lllll}
\hline Samples & Add $(\mu \mathrm{M})$ & $\begin{array}{l}\text { Found } \\
(\mu \mathrm{M})\end{array}$ & $\begin{array}{l}\text { Recovery } \\
(\%)\end{array}$ & $\begin{array}{l}\text { RSD }(\%) \\
(n=3)\end{array}$ \\
\hline Tomato & 0 & 3.86 & - & 2.5 \\
& 5.00 & 8.57 & 94.2 & 5.3 \\
& 10.00 & 14.36 & 105 & 6.6 \\
\multirow{5}{*}{ Ketchup } & 20.00 & 24.46 & 103 & 4.6 \\
& 0 & 0.63 & - & 4.6 \\
& 5.00 & 5.19 & 91.2 & 1.7 \\
& 10.00 & 10.49 & 98.4 & 3.4 \\
& 20.00 & 19.99 & 96.8 & 5.0
\end{tabular}

with the declared content. The recoveries for spiked GSH are $91.2 \%$ to $105 \%$, which is acceptable. This indicates that the PEC sensor can be used for the detection of GSH in real samples.

\section{Conclusions}

In summary, a GR/CdS:Mn composite has been synthesized and characterized. The detail states of the additives and their specific effects have been discussed. The GR/CdS:Mn composite demonstrates good PEC properties and low photo-corrosion and the resulting PEC sensor displays sensitive and selective response to GSH under visible illumination at $0 \mathrm{~V}$. This is related to the doped $\mathrm{Mn}^{2+}$ and the introduced GR, which effectively improve the separation of photo-induced charges. Under the optimized conditions, the ITO/GR/CdS:Mn sensor presents wide detection range of $0.01 \mu \mathrm{M}$ to $100 \mu \mathrm{M}$, a low detection limit of $0.01 \mu \mathrm{M}$, as well as good reproducibility. It can be used for the detection of GSH in real samples.

\section{Conflicts of interest}

There are no conflicts to declare.

\section{Acknowledgements}

The work was financially supported by the National Natural Science Foundation of China (Grant No. 21675117). The authors appreciate the Analytical and Testing Center of WHU for the help in material characterization.

\section{References}

1 A. Meister and M. E. Anderson, Annu. Rev. Biochem., 1983, 52, 711-760.

2 P. S. Samiec, C. Drews Botsch, E. W. Flagg, J. C. Kurtz, P. Sternberg Jr, R. L. Reed and D. P. Jones, Free Radical Biol. Med., 1998, 24, 699-704.

3 R. Deng, X. Xie, M. Vendrell, Y. T. Chang and X. Liu, J. Am. Chem. Soc., 2011, 133, 20168-20171.

4 J. T. Michaelsen, S. Dehnert, D. Giustarini, B. Beckmann and D. Tsikas, J. Chromatogr. B: Anal. Technol. Biomed. Life Sci., 2009, 877, 3405-3417.

5 M. H. Pournaghi Azar and F. Ahour, J. Electroanal. Chem., 2008, 622, 22-28.

6 A. Safavi, N. Maleki, E. Farjami and F. A. Mahyari, Anal. Chem., 2009, 81, 7538-7543.

7 S. M. Senthil Kumar and K. Chandrasekara Pillai, Electrochim. Acta, 2009, 54, 7374-7381.

8 J. C. Harfield, C. Batchelor McAuley and R. G. Compton, Analyst, 2012, 137, 2285-2296.

9 E. Katelhon and R. G. Compton, Analyst, 2014, 139, 24112415.

10 W. W. Zhao, X. D. Yu, J. J. Xu and H. Y. Chen, Nanoscale, 2016, 8, 17407-17414.

11 W. W. Zhao, J. J. Xu and H. Y. Chen, Chem. Soc. Rev., 2015, 44, 729-741. 
12 W. W. Zhao, J. J. Xu and H. Y. Chen, Chem. Rev., 2014, 114, 7421-7441.

13 H. Li, J. Li, Q. Xu and X. Hu, Anal. Chem., 2011, 83, 96819686.

14 Z. Kang, X. Yan, Y. Wang, Y. Zhao, Z. Bai, Y. Liu, K. Zhao, S. Cao and Y. Zhang, Nano Res., 2016, 9, 344-352.

15 G. L. Wang, K. L. Liu, Y. M. Dong, X. M. Wu, Z. J. Li and C. Zhang, Biosens. Bioelectron., 2014, 62, 66-72.

16 F. Jafari, A. Salimi and A. Navaee, Electroanalysis, 2014, 26, 1782-1793.

17 X. Li, J. Yu and M. Jaroniec, Chem. Soc. Rev., 2016, 45, 26032636.

18 Q. Shen, L. Han, G. Fan, J. R. Zhang, L. Jiang and J. J. Zhu, Anal. Chem., 2015, 87, 4949-4956.

19 P. K. Santra and P. V. Kamat, J. Am. Chem. Soc., 2012, 134, 2508-2511.

20 W. Tu, Y. Zhou and Z. Zou, Adv. Funct. Mater., 2013, 23, 49965008.

21 A. Nag, S. Chakraborty and D. D. Sarma, J. Am. Chem. Soc., 2008, 130, 10605-10611.

22 S. Zhou, Y. Kong, Q. Shen, X. Ren, J. R. Zhang and J. J. Zhu, Anal. Chem., 2014, 86, 11680-11689.

23 P. Wu, J. B. Pan, X. L. Li, X. Hou, J. J. Xu and H. Y. Chen, Chem.-Eur. J., 2015, 21, 5129-5135.

24 Z. Gao, N. Liu, D. Wu, W. Tao, F. Xu and K. Jiang, Appl. Surf. Sci., 2012, 258, 2473-2478.

25 A. Cao, Z. Liu, S. Chu, M. Wu, Z. Ye, Z. Cai, Y. Chang, S. Wang, Q. Gong and Y. Liu, Adv. Mater., 2010, 22, 103-106.

26 S. Oros Ruiz, A. Hernández Gordillo, C. García Mendoza, A. A. Rodríguez Rodríguez and R. Gómez, J. Chem. Technol. Biotechnol., 2016, 91, 2205-2210.

27 Q. Shen, X. Shi, M. Fan, L. Han, L. Wang and Q. Fan, J. Electroanal. Chem., 2015, 759(Part 1), 61-66.

28 N. Zhang, M. Q. Yang, Z. R. Tang and Y. J. Xu, J. Catal., 2013, 303, 60-69.

29 L. B. Abdulra'uf, M. K. Chai and G. H. Tan, J. AOAC Int., 2012, 95, 1272-1290.

30 N. Yan, Z. Zhu, N. Ding, L. Zhou, Y. Dong and X. Chen, J. Chromatogr. A, 2009, 1216, 8665-8670.

31 H. Wang, H. Ye, B. Zhang, F. Zhao and B. Zeng, J. Mater. Chem. A, 2017, 5, 10599-10608.

32 T. Nakajima, A. Mabuchi and R. Hagiwara, Carbon, 1988, 26, 357-361.
33 X. Zhao, S. Zhou, Q. Shen, L. P. Jiang and J. J. Zhu, Analyst, 2012, 137, 3697-3703.

34 Q. Li, B. Guo, J. Yu, J. Ran, B. Zhang, H. Yan and J. R. Gong, J. Am. Chem. Soc., 2011, 133, 10878-10884.

35 S. Kolhe, S. K. Kuljarni, A. S. Nigavekar and S. K. Sharma, Sol. Energy Mater., 1984, 10, 47-54.

36 J. Yu, Y. Yu, P. Zhou, W. Xiao and B. Cheng, Appl. Catal., B, 2014, 156, 184-191.

37 H. Franzen and C. Sterner, J. Solid State Chem., 1978, 25, 227-230.

38 H. van der Heide and C. F. van Bruggen, Mater. Res. Bull., 1982, 17, 1517-1521.

39 H. L. Guo, X. F. Wang, Q. Y. Qian, F. B. Wang and X. H. Xia, ACS Nano, 2009, 3, 2653-2659.

40 Y. Si and E. T. Samulski, Nano Lett., 2008, 8, 1679-1682.

41 B. E. Boone and C. Shannon, J. Phys. Chem., 1996, 100, 94809484.

42 P. Q. Zhao, L. Z. Liu, H. T. Xue, X. L. Wu, J. C. Shen and P. K. Chu, Appl. Phys. Lett., 2013, 102, 061910.

43 Y. Chen, J. Fang, S. Lu, W. Xu, Z. Liu, X. Xu and Z. Fang, J. Chem. Technol. Biotechnol., 2015, 90, 947-954.

44 C. M. McShane and K. S. Choi, J. Am. Chem. Soc., 2009, 131, 2561-2569.

45 Y. An, L. Tang, X. Jiang, H. Chen, M. Yang, L. Jin, S. Zhang, C. Wang and W. Zhang, Chem.-Eur. J., 2010, 16, 1443914446.

46 J. Tang, B. Kong, Y. Wang, M. Xu, Y. Wang, H. Wu and G. Zheng, Nano Lett., 2013, 13, 5350-5354.

47 W. Tu, Y. Dong, J. Lei and H. Ju, Anal. Chem., 2010, 82, 87118716.

48 N. Zhang, M. Q. Yang, Z. R. Tang and Y. J. Xu, ACS Nano, 2014, 8, 623-633.

49 J. C. Ndamanisha, J. Bai, B. Qi and L. Guo, Anal. Biochem., 2009, 386, 79-84.

50 J. Li, H. Li, Y. Xue, H. Fang and W. Wang, Sens. Actuators, B, 2014, 191, 619-624.

51 G. Chen, J. Wang, C. Wu, C. Z. Li, H. Jiang and X. Wang, Langmuir, 2012, 28, 12393-12399.

52 C. Antwi, A. S. Johnson, A. Selimovic and R. S. Martin, Anal. Methods, 2011, 3, 1072-1078.

53 Y. Wang, J. Lu, L. Tang, H. Chang and J. Li, Anal. Chem., 2009, 81, 9710-9715. 